\title{
Colligo App: gamificação em sala de aula
}

\author{
Alice M. Wiener ${ }^{1}$, Aline de Campos $^{2}$ \\ ${ }^{1}$ Instituto de Pesquisas Eldorado - Porto Alegre - RS - Brasil \\ ${ }^{2}$ Programa de Pós-graduação em Informática na Educação - Universidade Federal do \\ Rio Grande do Sul - Porto Alegre - RS - Brasil \\ \{alicewiener, alinedecampos\}@gmail.com
}

\begin{abstract}
Resumo. O Colligo é um aplicativo para dispositivos móveis destinado ao uso em sala de aula com suporte a técnicas de gamificação que podem apoiar os processos de aprendizagem. Através de questionários, pontuações, emblemas e conquistas o aplicativo possibilita estimular a interação e integração entre professores e alunos de forma lúdica e engajadora. Além disso, serve como auxílio na tomada de decisão por parte dos docentes, no sentido de poder oferecer práticas diferenciadas de acordo com o perfil da turma. O protótipo do aplicativo está disponível para as plataformas iOS e Android e em aplicações experimentais em sala de aula mostrou-se com alta aceitação e com grande potencial para expansão.
\end{abstract}

\section{Cenário de uso}

O cenário educacional vem se desenvolvendo em conjunto com a popularização do acesso aos dispositivos móveis e a conexão com internet. Assim, abre-se espaço para estratégias pedagógicas que possam usar o potencial das tecnologias de informação e comunicação. Segundo a UNESCO (2013) a aprendizagem mobile, também chamada de Mobile Learning ou M-Learning, pode ser definida como o ensino que envolve uso de aparelhos digitais e portáteis, onde recursos educacionais podem ser acessados a qualquer hora e lugar, possibilitando maior integração dentro e fora de sala de aula .

Além disso este tipo de suporte pode ter diversos benefícios para o ambiente educacional, tais como: a) facilitar avaliação imediata, podendo o aluno tomar uma iniciativa quanto aos conteúdos que deve rever; b) promover processos de aprendizagem personalizada; c) maximizar a busca de conhecimento suplementar; d) auxiliar estudantes com dificuldades físicas, de aprendizagem ou emocionais; e) melhorar comunicação entre professor e aluno; f) fornecer recursos para o uso produtivo do tempo em sala de aula; g) apoiar o estudante em diferentes espaços físicos; h) possibilitar de uma aprendizagem contínua [UNESCO, 2013].

Indo ao encontro deste contexto, em diversos âmbitos são cada vez mais adotadas técnicas como a gamificação, que segundo Domínguez et al. (2013) é a utilização "de elementos e mecânicas de jogos, em um contexto que não seja de jogo". $\mathrm{Ou}$ seja, ao se fazer uso de mecanismos encontrados em jogos, como regras, premiações, pontuações, ranking pode-se estimular nos participantes aspectos de motivação e engajamento. Em se tratando do uso de gamificação em sala de aula, um dos maiores desafios reside em fazer com que os elementos de jogos potencializem o aprendizado e não fiquem restritos apenas ao entretenimento. 
Diante do potencial do uso de aplicativos para dispositivos móveis em âmbito educacional, a adoção de práticas de gamificação nos mais diversos processos e a pouca expressão desta integração no cenário atual, foi concebido o aplicativo Colligo. Fundamentado em teorias educacionais e com interface e usabilidade atrativa a diversos públicos, visa promover interação entre professores e alunos através da gamificação e auxiliar no processo educacional, levando em consideração aspectos de perspectiva humanista, onde os elementos adicionados estimulam o foco na satisfação, busca por objetivos e crescimento técnico e pessoal do aluno, onde os sentimentos e ações são integrados.

Como principal funcionalidade apresentam-se os questionários para aplicação em sala de aula com feedback imediato ao docente, indo ao encontro da relação estímulo-resposta, sendo esta capaz de instigar a reflexão de entendimento dos conteúdos e possibilitando ao docente a perspectiva de avaliação da absorção dos diversos assuntos por parte de seus alunos. Abre-se a possibilidade ao docente de traçar estratégias pedagógicas em tempo real e com esse conceito, os alunos serão motivados ao estudo, reforçando conhecimento e recebendo feedback [Fadel, 2014].

Para estímulo à participação e ludificação dos processos pedagógicos em sala de aula, são apresentados elementos de gamificação como pontuações, ranking, emblemas e cartas. Estes recursos podem estimular o aluno a aprender mais para atingir objetivos e realizar conquistas. Também, motivar e despertar a autonomia no aluno, uma fundamentação centrada nas teorias construtivistas para expressões de valorização das ações do aluno pelo professor.

O docente pode criar e gerenciar suas turmas, desenvolver questionários dos assuntos que considerar mais relevantes, criar e apresentar cronograma de aulas, controlar a presença de alunos, enviar arquivos com materiais didáticos ou conteúdos complementares que poderão ser acessados em qualquer lugar, bem como enviar avisos e manter uma aproximação maior com seus alunos.

O aplicativo foi concebido de forma a ser configurável, tanto no que diz respeito a sua interface, como a escolha de cores diferentes para cada turma, quanto nas funcionalidades disponíveis. Assim, o docente tem a liberdade de analisar o perfil de sua turma e verificar quais funções se enquadram melhor para cada grupo de alunos, já que são diferentes e podem reagir de formas diferentes a cada estímulo.

Por se tratar de um aplicativo voltado ao estímulo de processos de interação com o uso de estratégia de jogos, o Colligo pode ser aplicado em diferentes disciplinas, uma vez que apresenta suas funcionalidades customizáveis. Sendo assim, pode-se focar no desenvolvimento de uma motivação extrínseca que se inicia da vontade do sujeito de obter uma recompensa externa, mas também estimular o desenvolvimento da motivação intrínseca, que se apresenta como mais difícil de ser alcançada, uma vez que advém da curiosidade, mas que apresenta indícios concretos de que a metodologia pode auxiliar os estudantes a se tornarem automotivados [Zichermann e Cunningham, 2011].

Sendo assim, o Colligo apresenta como público alvo professores e alunos dos diversos níveis educacionais que busquem uma alternativa de criação de processos pedagógicos ativos e lúdicos com o uso de gamificação para estimular interações e aprendizados. 
VII Congresso Brasileiro de Informática na Educação (CBIE 2018)

Anais dos Workshops do VII Congresso Brasileiro de Informática na Educação (WCBIE 2018)

\section{Desenvolvimento}

Esse projeto surgiu da percepção da crescente adoção de dispositivos móveis, cada vez mais populares e acessíveis, em contraponto com sua falta de adoção em âmbito educacional. Sendo assim, verificou-se o potencial pedagógico no desenvolvimento de um aplicativo que pudesse integrar docentes e alunos de forma lúdica e engajadora através de técnicas de gamificação. Para tanto, foram analisados projetos correlatos que pudessem situar de maneira mais assertiva o direcionamento do conjunto de funcionalidades a serem implementadas.

Realizou-se a projeção de funcionalidades e criou-se o Product Backlog tendo em vista a relevância pedagógica do aplicativo através do estudo de cenários de educação com uso de metodologias ativas, referências sobre teorias educacionais que pudessem embasar as escolhas, bem como conversas com docentes e alunos em busca de sua percepção sobre o assunto.

O conjunto de funcionalidades elencadas foi priorizado de acordo com sua relevância para o projeto, seguindo sempre a linha da corrente crítica: onde primeiramente se realizam as atividades com maior impacto e com estimativa maior, diminuindo o risco no projeto e falhas. A partir disso foram estruturados ciclos de trabalho, usando práticas da metodologia de gerenciamento de desenvolvimento de sistemas Scrum [Rubin, 2012].

A cada início de ciclo, denominado Sprint, foram selecionadas funcionalidades a serem desenvolvidas no próximo ciclo. Assim, foram escritas no formato de Histórias de Usuário, especificando o papel, a funcionalidade e o motivo, além de descrever critérios de aceitação. No final de cada sprint ocorreram os processos de sprint review (foco no produto), sprint retrospective (foco no processo) e planning (foco nos próximos passos) [Rubin, 2012]. Em um primeiro momento realiza-se a avaliação quanto aos critérios de aceitação das funcionalidades desenvolvidas e levantamento dos erros e acertos do último ciclo.

Foram utilizadas tecnologias voltadas para criação de aplicativos para dispositivos móveis com sistema operacional iOS e Android. A versão iOS foi desenvolvida em Swift e conta com todas as funcionalidades descritas anteriormente. E para a versão Android foi utilizado o framework React Native e encontra-se em fase final de desenvolvimento, sendo apresentadas até o momento as funcionalidades referentes ao aluno. Portanto, com o aplicativo Android é possível entrar em turmas, visualizar e responder questionários, visualizar emblemas e cartas e visualizar notificações.

\section{Apresentação do Software}

O projeto foi desenvolvido com o foco no professor e no aluno. O usuário, após realizar o registro ou autenticação é encaminhado para a lista de turmas (tela a esquerda da Figura 1). Quando uma nova turma é criada (tela ao centro da Figura 1), pode-se definir cores, informações gerais e escolher quais funcionalidades devem estar ativadas para essa turma. Com essas opções configuráveis o professor pode definir o que considera mais adequado conforme a necessidades da turma. Após criada a turma, tanto professor, quanto aluno podem acessá-la e visualizar suas informações (tela a direita da Figura 1). 

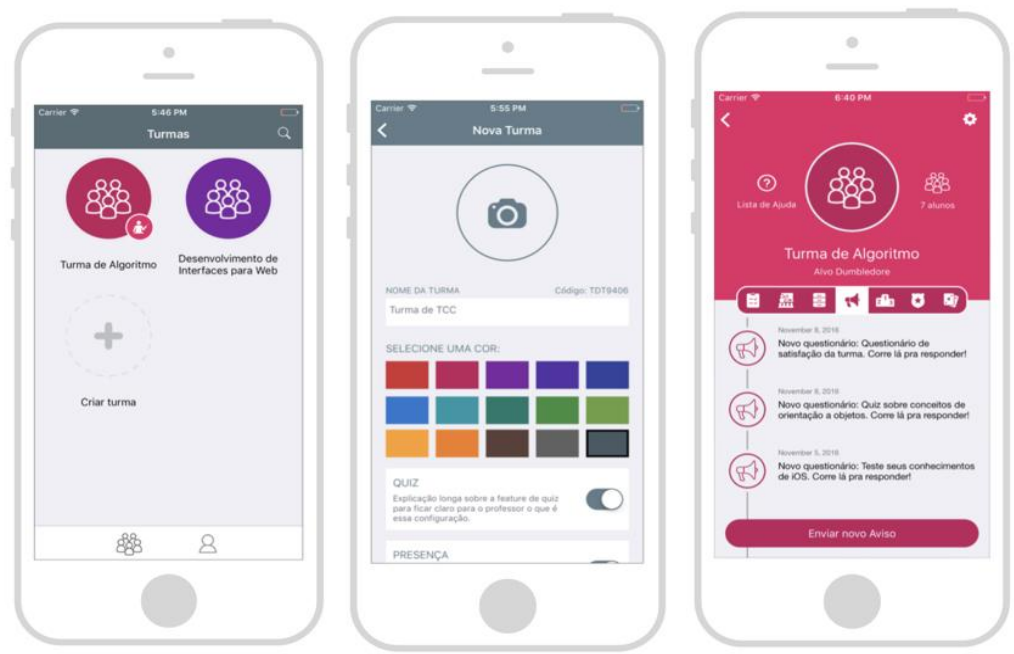

Figura 1. a) Interface para visualizar turmas (esquerda); b) criar novas turmas (centro); c) visualizar detalhes da turma (direita);

Se a funcionalidade de questionários for habilitada será então possível cadastrar questionários e enviá-los para a turma. Este recurso possibilita a criação de perguntas com respostas de múltipla escolha onde pode ser definida a resposta correta, bem como a quantidade de pontos que o aluno receberá caso acerte. Pode-se também definir se a resposta correta deve ser mostrada ao aluno depois de cada pergunta respondida, ao finalizar o questionário ou ainda se não devem ser mostradas. Dessa forma, o professor tem liberdade para conduzir o processo educacional conforme sua necessidade.

A lista de questionários enviados para a turma pode ser visualizada pelos alunos e professores (primeira tela da Figura 2), sendo assim os alunos responderão às perguntas (segunda tela na Figura 2) e ao finalizar o questionário uma mensagem e um gif animado será mostrado (terceira tela na Figura 2). Essa animação é personalizada para a pontuação que o aluno alcançou com o questionário respondido. No entanto, mesmo que o aluno não tenha conseguido uma boa pontuação, a animação deverá motivar o aluno a participar novamente. Enquanto a turma responde ao questionário, o professor pode visualizar o gráfico de respostas com a porcentagem de alunos que escolheram as alternativas (quarta tela na Figura 2). Além disso, o professor pode visualizar a lista de alunos que responderam e quais as alternativas eles escolheram e dessa forma, pode avaliar rapidamente o andamento da aula e visualizar quais assuntos necessitam ser revisados. O questionário pode ser disponibilizado para jogar, sendo assim os alunos podem respondê-lo mais de uma vez, podendo assim retomar seus conhecimentos em um determinado assunto também fora da sala de aula. 
VII Congresso Brasileiro de Informática na Educação (CBIE 2018)

Anais dos Workshops do VII Congresso Brasileiro de Informática na Educação (WCBIE 2018)
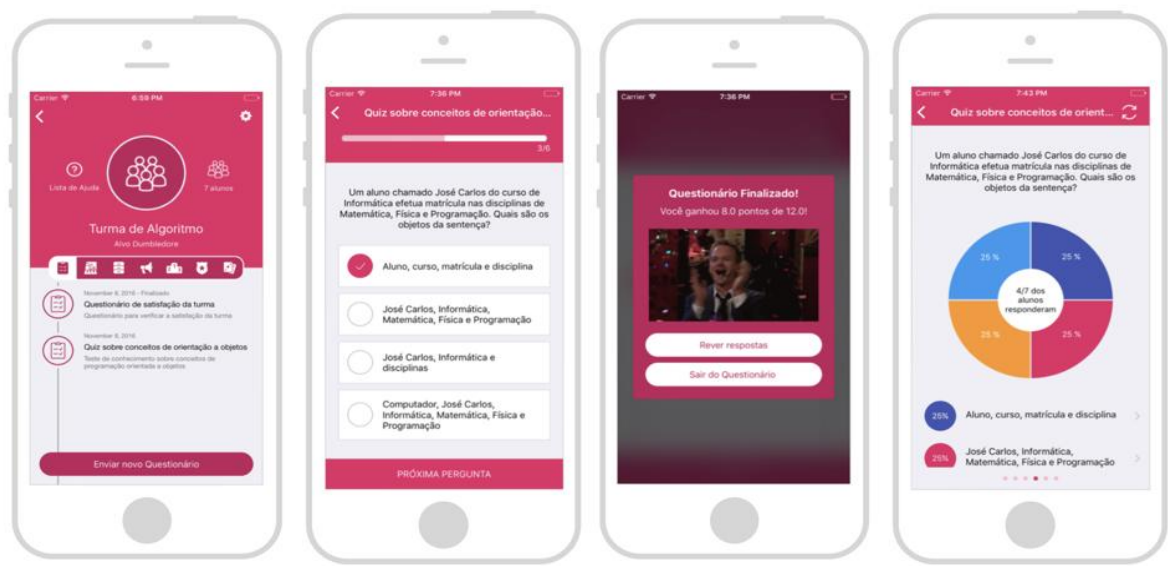

Figura 2. a) Interface para visualizar questionários (tela 1); b) responder questionário (tela 2); c) finalização do questionário (tela 3); d) visualizar resultados (tela 4);

Como forma de ajudar na gestão das aulas o professor pode escolher realizar o controle de presença ${ }^{1}$ do aluno dentro do aplicativo. Nesse caso, precisa criar as aulas, podendo assim definir uma descrição dos conteúdos e estabelecer um cronograma, sendo essas informações disponibilizadas para o aluno (tela à esquerda na Figura 3). Na funcionalidade de envio de arquivos (tela ao centro da Figura 3), através da integração com o Google Drive, pode-se facilitar o acesso a recursos didáticos e complementares.

Caso a funcionalidade de ranking (tela à direita na Figura 3) seja configurada para a turma a posição dos alunos com relação aos pontos conquistados será mostrada para os alunos. Dessa forma, o professor pode incentivar o estudo através da gamificação. O professor pode dar pontos extras para os alunos por uma determinada atividade ou conquista. O ranking, portanto, é formado a partir do resultado dos questionários e dos pontos extras.
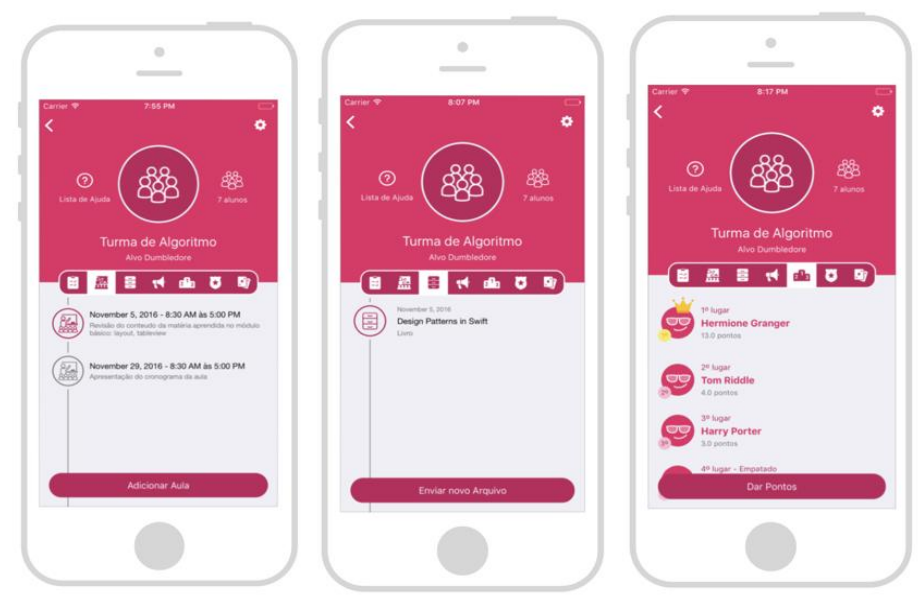

Figura 3. a) Interface para visualizar presenças (esquerda); b) visualizar arquivos (centro); c) visualizar ranking (direita);

\footnotetext{
${ }^{1}$ Na versão para iOS, pode-se dispor do controle de presença automático, ou seja, quando o horário da aula iniciar, o aplicativo do professor enviará um sinal para os dispositivos próximos, realizando assim a verificação de presença do aluno. Faz-se uso da tecnologia iBeacon que utiliza de Bluetooth Low Energy (BLE) para que um dispositivo consiga enviar um sinal e este seja captado por outro dispositivo em um raio de 70 metros.
} 
VII Congresso Brasileiro de Informática na Educação (CBIE 2018)

Anais dos Workshops do VII Congresso Brasileiro de Informática na Educação (WCBIE 2018)

Outra funcionalidade que pode ser habilitada é a de conquista de emblemas para os alunos, recurso de gamificação onde o jogador obtém status socialmente pelo esforço realizado, também conhecido como badges (primeira tela na Figura 4). Inicialmente são oferecidos ao professor alguns badges pré-definidos. Por exemplo, no caso de um aluno acertar todas as perguntas de um questionário por duas vezes consecutivas, ele pode ganhar um badge. Este recurso pode colaborar também para alertar o aluno de um certo comportamento de forma lúdica. Um dos emblemas pré-definidos é o do "Entrevistador" (segunda tela na Figura 4), que procura indicar de forma bem humorada que o aluno está conversando demais em aula, dessa forma o professor pode dar alguns feedbacks para os alunos de maneira divertida.

Outro mecanismos da gamificação é a conquista ou achievements, quando se chega a um nível ou, no contexto da sala de aula, se realiza uma atividade extra (terceira tela na Figura 4). Conforme configuração do professor, existe a possibilidade de oferecer aos alunos conquista de cartas (quarta tela na Figura 4). Essas cartas estarão no perfil do aluno até que ele as utilize. Por exemplo, o professor libera uma carta para quem realizar uma atividade extraclasse. Na carta, o aluno conquista a possibilidade de aumentar em um ponto a nota de um trabalho ou prova e pode escolher quando utilizar. Essa sensação de conquista está ligada também ao sentimento de propósito de se envolver em uma atividade, bem como estímulo a autonomia.
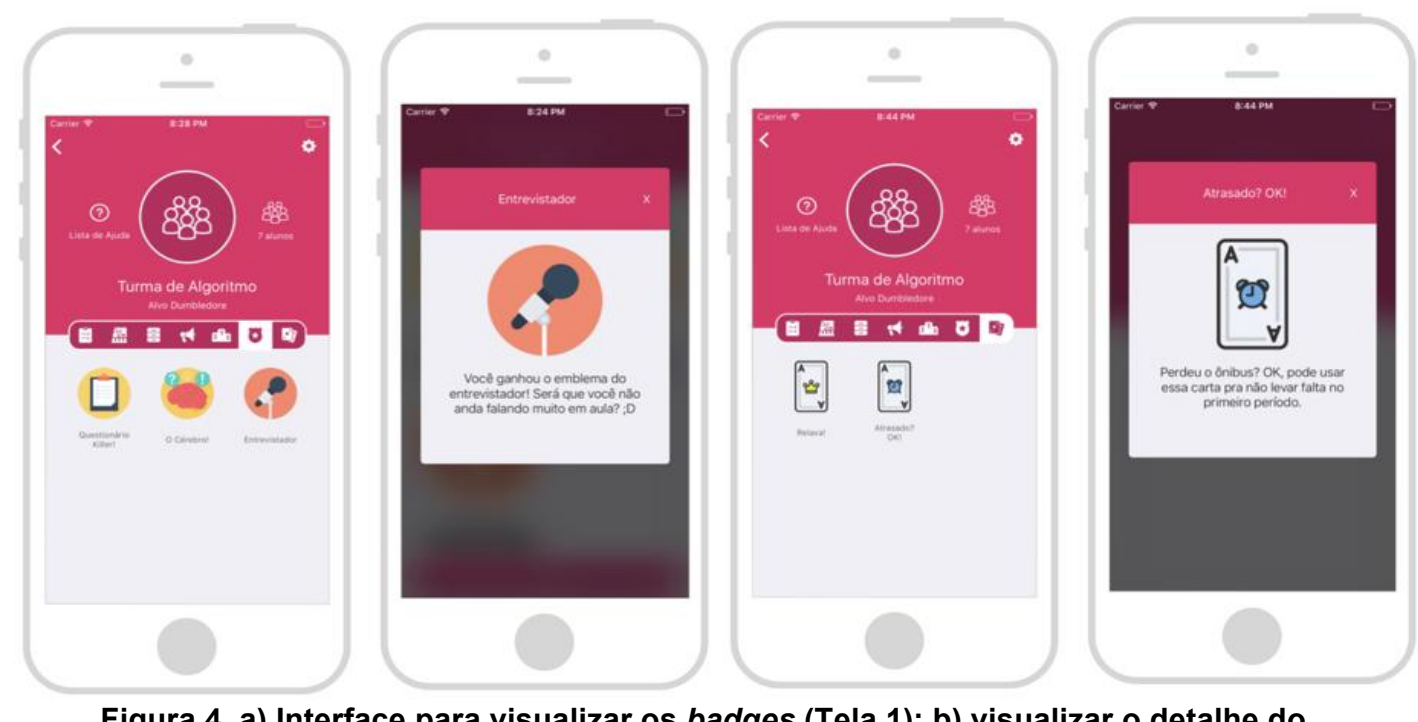

Figura 4. a) Interface para visualizar os badges (Tela 1); b) visualizar o detalhe do badge (Tela 2); c) visualizar as cartas (Tela 3); d) visualizar o detalhe da carta (Tela 4).

\section{Considerações finais}

Percebe-se o desejo por práticas mais interativas e estimulantes no âmbito educacional, tanto por parte de professores, quanto de alunos. Nos mais diversos níveis educacionais, o uso de metodologias ativas vem se intensificando, como forma de engajar alunos na construção de seu conhecimento e ampliar as possibilidades de atuação docente enquanto guia neste processo. A adoção de dispositivos móveis em conjunto com técnicas de gamificação indica a possibilidade de oferecer recursos adaptáveis a diversos públicos e lúdicos o bastante para captar a atenção dos envolvido. Assim, percebe-se o potencial do Colligo App enquanto alternativa gratuita para aplicação de gamificação através de dispositivos móveis em sala de aula. 
Foram realizados experimentos preliminares em cenários educacionais de Ensino Superior como forma de avaliar algumas características do projeto e buscar sugestões de melhorias e novas funcionalidades. Embora o aplicativo não seja destinado apenas ao Ensino Superior, escolheu-se esse público pelo acesso e ambiente disponível para aplicação. Participaram 56 alunos numa faixa etária entre 18 e 30 anos, em sua maioria alunos de cursos na área de Tecnologia da Informação.

Após a utilização prática em atividades de sala da aula, realizou-se a aplicação de um instrumento de coleta de dados em formato de questionário quantitativo usando a escala Likert de cinco pontos que seguiu as cinco métricas de Qualidade em Uso da ISO 25000 (SQuaRe) verificando eficácia, eficiência, satisfação, mitigação de risco e cobertura de contexto [ISO, 2008]. Em acréscimo, foram realizadas perguntas relativas sobre o uso do aplicativo em sala de aula como apoio em atividades pedagógicas, buscando verificar possíveis impactos no processos de aprendizagem, na motivação e engajamento.

Nas questões voltadas a avaliação das funcionalidades do projeto obteve-se cerca de $80 \%$ de satisfação. Interessante analisar que a maioria gostaria de utilizar o aplicativo em sala de aula, porém no que diz respeito ao estímulo para participação em aula, houve um grau de discordância ou neutralidade de resposta correspondente a $15 \%$. Embora o haja um alto grau de concordância, cabe a avaliação de melhorias no sentido de estimular a participação em aula. Uma observação feita por um dos alunos foi a falta de "anonimato", uma vez que existem diferentes perfis, havendo os que podem se sentir intimidados pela exposição em um ranking, por exemplo.

A experiência de realizar uma validação onde é possível observar o usuário interagindo com o aplicativo foi bastante valiosa. Foi possível observar como era a expectativa do usuário para um determinado componente ou tela e qual era a sua reação quanto ao feedback do aplicativo. A partir disso foram realizados alguns ajustes de interface e usabilidade que colaboraram com a melhoria na experiência do usuário.

Além disso, foi igualmente interessante observar a interação entre os alunos e com o professor durante a validação. Os alunos mostraram-se bastante animados para responder os questionários e, ao verem que o havia um ranking, solicitaram que a professora enviasse mais questões para que pudessem responder e receber mais pontos. Além disso, houve uma reação lúdica dos alunos quanto aos emblemas e cartas. Algumas cartas permitiam que o aluno faltasse uma aula ou não precisasse apresentar um trabalho. Alguns alunos pediram para que o aplicativo fosse utilizado realmente na disciplina para que pudessem fazer uso das cartas.

Observar e analisar a interação entre os participantes e poder conversar com os participantes depois da experimentação foi muito importante para a definição das próximas etapas do projeto. Essa troca de ideias e experiências certamente fará com que o aplicativo melhore no futuro e permita que novos usuários tenham uma experiência ainda mais produtiva.

Da mesma forma, levou-se em consideração a opinião de docentes sobre o Colligo e sua adoção em sala de aula. Após a demonstração do aplicativo em um vídeo encaminhou-se um questionário com os mesmos moldes do aplicado aos alunos, entretanto com foco em identificar a aplicabilidade dessa ferramenta em suas práticas docentes. Participaram 12 professores de diversos níveis de ensino, sendo a maior parte deles com mais de seis anos de experiência docente. Cerca de $90 \%$ acredita que a 
VII Congresso Brasileiro de Informática na Educação (CBIE 2018)

Anais dos Workshops do VII Congresso Brasileiro de Informática na Educação (WCBIE 2018)

aplicação pode auxiliar na percepção quanto às dúvidas dos alunos, oferece recursos para estimular a proatividade e automotivação ao estudo por parte dos alunos e possibilita que o professor utilize técnicas de gamificação em sala de aula. Os participantes demonstraram abertura a essa nova forma de interação através do aplicativo, além disso foi possível confirmar a relevância das perspectivas teóricas que o fundamentaram.

Em se tratando de um aplicativo construído com tecnologias híbridas, tem-se atualmente um protótipo completo com interface de docente e de aluno para dispositivos móveis iOS e o protótipo Android com interface do aluno e processo de finalização da interface docente. Há previsão de no futuro do projeto implementar uma versão web que inicialmente será para professores a fim de facilitar a criação de conteúdo para uso no aplicativo. Pretende-se em breve realizar experimentações em outros níveis de ensino, como Fundamental e Médio, a fim de verificar a aceitação pelos diversos públicos do projeto. Além disso, busca-se identificar demandas diferentes de acordo com cada contexto e que possam ser implementadas no aplicativo posteriormente.

\section{Referências}

Domínguez, A.; Navarrete, J. S.; Marcos, L.; Sanz, L. F.; Pagés, C.; Herráiz, J. J. M. (2013). "Gamifying learning experiences: Practical implications and outcomes". In Journal Computers \& Education, p. 380-392.

Fadel, L. M.; Ulbricht, V. R.; Batista, C. R.; Vanzin, T. (2014). "Gamificação na educação". São Paulo: Pimenta Cultural.

ISO - International Organization for Standardization. (2008). "ISO/IEC 25010 Software Engineering - Software Product Quality Requirements and Evaluation (SQuaRE): software and quality in use models". International Electrotechnical Commission.

Rubin, K. S. (2012). "Essential Scrum: A Practical Guide to the Most Popular Agile Process". Addison-Wesley Professional.

UNESCO. (2013). "Policy guidelines for mobile learning". http://unesdoc.unesco.org/images/0021/002196/219641e.pdf

Zichermann, G.; Cunningham, C. (2011). "Gamification by Design: Implementing Game Mechanics in Web and Mobile Apps". O’Reilly. 